\title{
Counting the cost: estimating the number of deaths among recently released prisoners in Australia
}

\author{
Stuart A Kinner, David B Preen, Azar Kariminia, Tony Butler, Jessica Y Andrews, Mark Stoové and Matthew Law
}

1 ustralia's prisoner population is growing at a rate well in excess of natural population growth. There were 29700 adults in full-time custody at 30 June 2010 , representing a $15 \%$ increase in the incarceration rate from 2000 to 2010. Women comprise $8 \%$ of adult prisoners but this proportion is increasing annually. Indigenous Australians are overrepresented by a factor of 14 , and the gap between Indigenous and non-Indigenous incarceration rates continues to widen. ${ }^{1}$

However, little is known about the large and growing number of ex-prisoners in the community. Data from the 2007 National Survey of Mental Health and Wellbeing suggest an ex-prisoner population of more than 385000 , representing 1.8\% of Australia's population, ${ }^{2}$ but the number released from custody each year is unknown. A recent study estimated 50405 adult prison separations in Australia during the 2007-08 financial year and called for improved data collection to inform health service planning for this profoundly marginalised group. ${ }^{3}$

The chronic, complex and often preventable health, social and economic marginalisation of prisoners in Australia has been well documented, ${ }^{4-9}$ as has the increased risk of death among those released from prison. ${ }^{10-13}$ Despite this, there is currently no mechanism in Australia to routinely monitor the incidence of mortality among ex-prisoners. It is thus difficult to gauge the impact of changes in correctional policy (such as the shift towards "throughcare" for prisoners ${ }^{14}$ ) or other risk factors (eg, Australia's heroin shortage, during which drug overdoses in the community fell by $40 \%-$ $85 \%{ }^{15}$ ) on mortality. Although health service planning for prisoners in Australia will benefit from the recently established national minimum dataset for prisoner health, ${ }^{16}$ the same cannot be said for the much larger population of ex-prisoners, who are excluded from this collection.

The most robust and efficient method of monitoring mortality outcomes for ex-prisoners is through routine record linkage, ${ }^{17}$ but this is not currently feasible at a national level in Australia. ${ }^{16}$ Using data from two state-based record-linkage studies ${ }^{10,11}$ and an estimate of the number and character-

\section{ABSTRACT}

Objective: To estimate the number of deaths among people released from prison in Australia in the 2007-08 financial year, within 4 weeks and 1 year of release.

Design, participants and setting: Application of crude mortality rates for ex-prisoners (obtained from two independent, state-based record-linkage studies [New South Wales and Western Australia]) to a national estimate of the number and characteristics of people released from prison in 2007-08.

Main outcome measures: Estimated number of deaths among adults released from Australian prisons in 2007-08, within 4 weeks and 1 year of release, classified by age, sex, Indigenous status and cause of death.

Results: It was estimated that among people released from prison in 2007-08, between $449(95 \% \mathrm{Cl}, 380-527)$ and $472(95 \% \mathrm{Cl}, 438-507)$ died within 1 year of release. Of these, between $68(95 \% \mathrm{Cl}, 56-82)$ and $138(95 \% \mathrm{Cl}, 101-183)$ died within 4 weeks of release.

Most of these deaths were not drug-related.

Conclusion: The estimated annual number of deaths among recently released prisoners in Australia is considerably greater than the annual number of deaths in custody, highlighting the extreme vulnerability of this population on return to the community. There is an urgent need to establish a national system for routine monitoring of ex-prisoner mortality and to continue the duty of care beyond the prison walls.

MJA 2011; 195: 64-68

istics of prison separations nationally over a 1-year period, ${ }^{18,19}$ we estimated the number of deaths among adults released from Australian prisons in the 2007-08 financial year, within 4 weeks and 1 year of release, and classified these deaths by age, sex, Indigenous status and cause of death.

\section{METHODS}

We estimated (i) the number and characteristics (age, sex, Indigenous status) of adult prison separations in Australia during 200708; (ii) the crude mortality rate (CMR) for exprisoners in Australia, within 4 weeks and 1 year of release, according to age, sex and Indigenous status, from two state-based Australian studies; and (iii) applied the corresponding CMRs to the estimated total number of prison separations to derive estimates of the number of deaths (and drug-related deaths) among this cohort within 4 weeks and 1 year of release. International Classification of Diseases (ninth and 10th revisions) codes for cause of death were categorised into drug-related, natural and all other causes, according to a system proposed by Randall and colleagues. ${ }^{20}$

\section{Estimating the number of prisoners released}

We obtained data from the Australian Bureau of Statistics disaggregating prisoner numbers in Australia at 30 June 2008 according to 5-year age group, sex and Indigenous status. ${ }^{18}$ Counts were converted into proportions of the total prisoner population, and these proportions were applied to the estimate of 50405 prison separations during $2007-08,{ }^{3}$ to estimate the number of prisoners released in 2007-08 overall and within each age, sex and Indigenous status stratum.

\section{Estimating crude mortality rates}

To estimate CMRs, data from two recent Australian record-linkage studies conducted in Western Australia and New South Wales were used. Comparable data were not available in any other Australian jurisdiction. The WA cohort $^{10}$ included all prisoners released from custody between 1 January 1994 and 31 December 1999 (16 162). Information on deaths up to 31 December 2003 was obtained from the WA Registrar General's record of deaths. The NSW cohort ${ }^{11}$ included all prisoners released 
from custody between 1 January 1988 and 31 December 2002 (82 650). Information on deaths up to 31 December 2002 was obtained from the National Death Index.

For each state-based study, estimation of CMRs proceeded through the following steps: - For each individual, the date of first release from custody during the follow-up period (the index release) was determined; follow-up periods of 4 weeks and 1 year were imposed from the date of index release, regardless of reimprisonment within these time frames.

- Within age, sex and Indigenous status strata, the number of deaths observed in the community within each period of observation was calculated. Deaths in custody were excluded.

- Within each stratum, total person-years (PY) of follow-up within each period of observation (irrespective of subsequent reimprisonment) was determined.

- Within each stratum and period of observation, a CMR was calculated as the observed number of deaths divided by PY of follow-up.

Estimating number of deaths nationally

To estimate the number of deaths nationally, within each stratum, we applied the corre-

\section{Characteristics of the Western Australian and New South Wales cohorts of released prisoners}

\begin{tabular}{lcc} 
& WA cohort & NSW cohort \\
\hline Years of release & $1994-2002$ & $1988-2002$ \\
Years of observed deaths & $1994-2003$ & $1988-2002$ \\
Sample size & 16162 & 82650 \\
$\geqslant 1$ subsequent release event & $37.7 \%$ & $46.1 \%$ \\
Imprisonment rate* & 230.3 & 195.3 \\
Indigenous & $34.7 \%$ & $11.1 \%$ \\
Men & $88.1 \%$ & $89.5 \%$ \\
Age & & \\
$<25$ years & $36.6 \%$ & $39.6 \%$ \\
$25-39$ years & $46.5 \%$ & $44.6 \%$ \\
$\geqslant 40$ years & $16.9 \%$ & $15.8 \%$ \\
No. of observed deaths & & \\
First 1 year after release & $143(20.5 \%)$ & $721(14.9 \%)$ \\
First 4 weeks after release & $44(6.3 \%)$ & $104(2.2 \%)$ \\
Total no. of deaths & 699 & 4827 \\
\hline
\end{tabular}

*Per 100000 adults in the financial year 2007-08. ${ }^{17}$

sponding CMRs from each state-based study to the estimated number of prison separations Australia-wide in 2007-08. Due to some small cell sizes ( $<10$ PY of observation), some estimates within strata were unstable, so we aggregated observed data and computed estimates based on the relevant (observed) marginal totals.

\section{RESULTS}

The characteristics of the WA and NSW cohorts are summarised in Box 1. The NSW cohort was much larger, with more years of observation and more than seven times as many observed deaths. More than a third of the WA cohort was Indigenous, compared with $11 \%$ of the NSW cohort.

Observed CMRs for the NSW and WA cohorts are shown in Box 2, along with the corresponding estimated number of deaths among ex-prisoners who were released in Australia in 2007-08, within 1 year of release, by age, sex and Indigenous status. The estimated total number of deaths nationally based on data from the NSW (472) and WA (449) cohorts was similar, as were most estimates within evaluated strata. One exception was deaths among Indigenous ex-prisoners, with the NSW-based estimate (152) being $45 \%$ greater than the WAbased estimate (105). This reflected the greater observed CMR among Indigenous ex-prisoners in NSW (12.42 per $1000 \mathrm{PY})$ compared with WA (8.61 per $1000 \mathrm{PY})$.

For each state cohort, Box 3 shows the percentage of observed deaths within 1 year of release occurring in each month, by sex and Indigenous status. In WA, 33\% of first-

2 Observed crude mortality rates and estimated number of deaths within 1 year of release among ex-prisoners in Australia released in the financial year 2007-08

\begin{tabular}{|c|c|c|c|c|c|}
\hline & \multirow{2}{*}{$\begin{array}{l}\text { Estimated no. } \\
\text { of separations }\end{array}$} & \multicolumn{2}{|c|}{ Observed crude mortality ratio* } & \multicolumn{2}{|c|}{ Estimated number of deaths nationally $(95 \% \mathrm{Cl})$} \\
\hline & & WA cohort & NSW cohort & WA estimate & NSW estimate \\
\hline Total & $50405^{3}$ & 8.90 & 9.36 & $449(380-527)$ & $472(438-507)$ \\
\hline \multicolumn{6}{|l|}{ Indigenous status } \\
\hline Indigenous & 12240 & 8.61 & 12.43 & 105 (79-139) & $152(131-176)$ \\
\hline Non-Indigenous ${ }^{\dagger}$ & 38165 & 9.07 & 8.65 & $346(282-421)$ & $330(303-359)$ \\
\hline \multicolumn{6}{|l|}{ Sex } \\
\hline Men & 46823 & 9.20 & 9.41 & $431(361-509)$ & $440(408-475)$ \\
\hline Women & 3582 & 6.78 & 8.97 & $24(14-40)$ & $32(25-40)$ \\
\hline \multicolumn{6}{|l|}{ Age } \\
\hline$<25$ years & 9704 & 6.62 & 7.22 & $64(46-87)$ & 70 (61-80) \\
\hline 25-39 years & 26118 & 8.98 & 9.73 & 235 (183-296) & $254(228-283)$ \\
\hline$\geqslant 40$ years & 14583 & 13.67 & 13.75 & 199 (142-272) & 201 (172-233) \\
\hline
\end{tabular}


3 Percentage of observed deaths among ex-prisoners in Western Australia* and New South Wales ${ }^{\dagger}$ in the first 12 months after release, by month, sex and Indigenous status
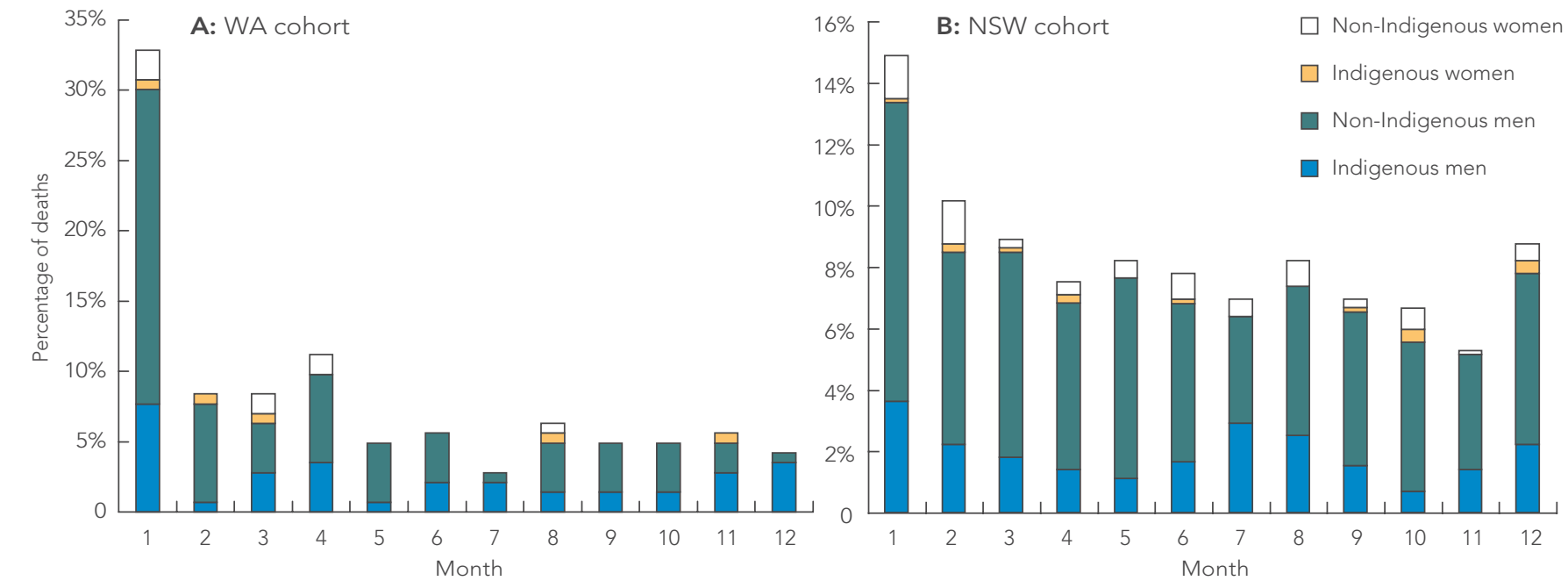

* Released 1994-1999. † Released 1988-2002.

year deaths occurred in the first month after release, with two-thirds of these (22\% of the total) occurring among non-Indigenous men. The percentage of deaths was also higher in the first month after release in NSW, although only $15 \%$ of deaths in the first year after release occurred by this time. Again, twothirds of these deaths ( $10 \%$ of the total) were among non-Indigenous men.

We also estimated the number of deaths occurring within 4 weeks of release (Box 4). Based on data from the WA cohort, we estimated that 138 people released from prison in Australia during 2007-08 died within 4 weeks of release, most of whom were non-Indigenous, male and $\geqslant 40$ years old. The NSW-based estimate was more conservative, with 68 ex-prisoners estimated to have died within 4 weeks of release. Most were non-Indigenous and male, but younger (< 40 years). The observed all-cause CMR within 4 weeks of release in WA (35.60 per 1000 PY) was more than twice that observed in NSW (17.54 per 1000 PY), driven principally by larger observed CMRs in the WA cohort for non-Indigenous, male exprisoners aged $\geqslant 40$ years.

The percentage of observed deaths in each cohort, within the first 4 weeks and 1 year after release, attributed to drug-related, natural and all other causes is shown in Box 5. In both jurisdictions, fewer than half of all deaths within 1 year after release were drug-related, although the percentage of drug-related deaths was higher among the NSW cohort in both the first year and the first 4 weeks. Conversely, the percentage of deaths due to natural causes was higher among the WA cohort.

\section{DISCUSSION}

Our study represents the most comprehensive attempt to date to estimate national mortality among recently released prisoners in Australia. We estimate that between 380 and 527 people released from prison in 2007-08 died within 1 year of release, with a disproportionate number dying in the first 4 weeks. These findings are consistent with

4 Observed crude mortality rate* and estimated number of deaths, within 4 weeks of release, among ex-prisoners in Australia released in the financial year 2007-08

\begin{tabular}{|c|c|c|c|c|c|}
\hline & \multirow[b]{2}{*}{$\begin{array}{l}\text { Estimated no. } \\
\text { of separations }\end{array}$} & \multicolumn{2}{|c|}{ Observed crude mortality ratio* } & \multicolumn{2}{|c|}{ Estimated number of deaths nationally $(95 \% \mathrm{Cl})$} \\
\hline & & WA cohort & NSW cohort & WA estimate & NSW estimate \\
\hline Total & $50405^{3}$ & 35.60 & 17.54 & $138(101-183)$ & $68(56-82)$ \\
\hline \multicolumn{6}{|l|}{ Indigenous status } \\
\hline Indigenous & 12240 & 27.97 & 22.39 & $26(14-45)$ & $21(14-31)$ \\
\hline Non-Indigenous ${ }^{\dagger}$ & 38165 & 39.66 & 16.41 & $116(81-162)$ & $48(38-60)$ \\
\hline \multicolumn{6}{|l|}{ Sex } \\
\hline Men & 46823 & 37.68 & 17.48 & 135 (98-182) & $63(51-77)$ \\
\hline Women & 3582 & 20.31 & 18.05 & $6(1-15)$ & $5(3-9)$ \\
\hline \multicolumn{6}{|l|}{ Age } \\
\hline$<25$ years & 9704 & 15.45 & 11.89 & $11(5-23)$ & $9(6-13)$ \\
\hline 25-39 years & 26118 & 34.82 & 21.13 & $70(44-106)$ & 42 (32-55) \\
\hline$\geqslant 40$ years & 14583 & 81.58 & 21.60 & 91 (55-144) & $24(15-37)$ \\
\hline
\end{tabular}


5 Percentage of observed deaths among released prisoners within 1 year and within 4 weeks of release, by cause of death

\begin{tabular}{lccccc} 
& \multicolumn{2}{c}{ WA cohort } & & \multicolumn{2}{c}{ NSW cohort } \\
\cline { 2 - 3 } \cline { 5 - 6 } Cause of death & $\begin{array}{c}\text { Within 1 year } \\
\text { of release }\end{array}$ & $\begin{array}{c}\text { Within 4 weeks } \\
\text { of release }\end{array}$ & & $\begin{array}{c}\text { Within 1 year } \\
\text { of release }\end{array}$ & $\begin{array}{c}\text { Within 4 weeks } \\
\text { of release }\end{array}$ \\
\hline Drug-related & $30.9 \%$ & $23.3 \%$ & & $44.5 \%$ & $51.0 \%$ \\
Natural & $25.2 \%$ & $27.9 \%$ & & $16.8 \%$ & $10.6 \%$ \\
All other causes & $43.9 \%$ & $48.8 \%$ & & $38.7 \%$ & $38.5 \%$
\end{tabular}

a growing body of international literature demonstrating an elevated risk of death in ex-prisoners, particularly in the first few weeks after release and often due to drugrelated causes. ${ }^{10-13,21-24}$

Although the two estimates of 1-year, allcause mortality were similar, there were important differences between the two cohorts. First, the WA-based estimate of mortality in the first 4 weeks was more than double the NSW-based estimate, largely due to differing estimates of mortality for nonIndigenous men aged $\geqslant 40$ years. There was also considerable heterogeneity in 1-year mortality estimates for Indigenous ex-prisoners, with the NSW-based estimate 45\% greater than the WA-based estimate. Clearly, further research is required to understand the factors associated with risk of death after release and to inform targeted, jurisdictionspecific, preventive interventions.

Second, the proportion of drug-related deaths was considerably higher in the NSW cohort, particularly in the first 4 weeks. Possible reasons for this include the greater availability of heroin in NSW than in WA, ${ }^{25}$ and the smaller proportion of Indigenous ex-prisoners, who are less likely to inject drugs ${ }^{16}$ or die of drug-related causes, ${ }^{26}$ in the NSW cohort. Conversely, members of the WA cohort were more likely to die of natural causes, which may be related to the high incidence of chronic disease and other morbidities among Indigenous ex-prisoners in WA. ${ }^{27} \mathrm{~A}$ third possible explanation may relate to jurisdictional differences in coding causes of death, with deaths in the first 4 weeks more likely to be coded as "other injury and poisoning" or "unspecified" in the WA cohort (28.0\%) than in the NSW cohort (6.7\%). If these deaths were also considered to be drugrelated, then the proportion of deaths in the first 4 weeks attributed to drug-related causes in NSW and WA would be similar.

Despite these jurisdictional differences, a large proportion of deaths in both cohorts was drug-related, highlighting the ongoing need to develop and implement evidence- based strategies to reduce drug-related death among ex-prisoners. One such strategy is opiate substitution therapy, which has been associated with reduced mortality, reincarceration and hepatitis $C$ infection in ex-prisoners. ${ }^{28}$ Yet, despite unambiguous endorsement of opiate substitution therapy in the National Corrections Drug Strategy 2006-2009, ${ }^{29}$ its provision in Australian prisons remains inconsistent. ${ }^{16}$ Another suggested approach is the provision of naloxone for peer administration. ${ }^{30,31}$ A clinical trial of naloxone provision to those at risk of overdose on release from prison has been proposed ${ }^{23}$ but not yet conducted.

Although drug overdose is a leading cause of death for recently released prisoners, more than $50 \%$ of deaths in this study were not drug-related, and at least two-thirds of deaths in the first year occurred more than 1 month after release. These findings underscore the importance of moving beyond simplistic messages about reduced drug tolerance and overdose risk in the first few weeks of release ${ }^{24}$ to build a more sophisticated, evidence-based approach to reducing mortality among ex-prisoners from multiple preventable causes over at least the first year after release. ${ }^{17}$ To be effective, preventive interventions must be multifaceted, cross-sectoral, tailored to the target group and, crucially, delivered both before and after release. ${ }^{14}$

Since the 1991 Royal Commission into Aboriginal Deaths in Custody, ${ }^{32}$ considerable attention has been devoted to monitoring deaths among Australian prisoners. According to the National Deaths in Custody Program, the annual number of prisoner deaths peaked at 76 in 1997, falling to 45 in $2007 .^{33}$ Our estimates for ex-prisoners are considerably greater and indicate a need for a comparable system to monitor deaths among ex-prisoners. Because our estimates are a function of prison separations, the indirect estimation method used here is unsuitable for future monitoring purposes. One cost-effective method for such surveillance would be through routine, national linkage with the
National Death Index, either as part of the new national minimum dataset for prisoner health $^{16}$ or to complement the National Deaths in Custody Program. ${ }^{33}$ There is growing recognition in Australia of the public health benefit of record linkage, ${ }^{34}$ and systems to protect the privacy of individuals are well established. ${ }^{35}$

Our study had several limitations, most of which would produce underestimation of mortality. First, by building on an already imperfect method (probabilistic record linkage), the estimates derived here have the same weaknesses as the original studies, including underascertainment of deaths due to failed linkage. The WA-based estimate is further compromised by linking only with state-based coronial records, thereby failing to detect deaths outside of WA. This is likely to produce systematic underestimation of deaths occurring with increased time after release from custody, which might explain the relatively greater proportion of deaths in the first month of release in the WA data.

Second, in the absence of available national data on prisoner releases, the number and demographic characteristics of those released were estimated. Built into this estimate is the imperfect assumption that the demographic profile of prison separations is the same as that of prisoners. Prison separations will overrepresent those serving shorter sentences that is, young people, Indigenous Australians and women. ${ }^{1}$ Given the lower CMRs observed among these groups, this would have produced underestimation of mortality. Third, because we did not consider deaths in custody or account for periods of reimprisonment within the year following release, the incidence of mortality was underestimated and time "at risk" was overestimated, resulting in underestimation of CMRs.

Two limitations of our method would produce overestimation of mortality. First, the CMRs applied to 2007-08 prison separations were derived from deaths occurring between 1994 and 2003 in WA and between 1988 and 2002 in NSW. Preliminary data from a similar record-linkage study in Queensland suggest that the incidence of drug-related mortality among ex-prisoners declined significantly following the onset of a national heroin shortage in 2001. ${ }^{36}$ This may have produced overestimation of mortality, or at least of drug-related mortality. Second, in the absence of alternative data, we used an estimate of prison separations as a proxy for the number of people released from prison in 2007-08. Because some individuals are released from prison multiple times within a 
year, this would have resulted in overestimation of the number of prisoners released in 2007-08, and thus overestimation of deaths.

A final limitation is reliance on data from two states to estimate mortality at the national level. Although our two estimates of mortality were similar and indirect estimation methods such as these are used widely, ${ }^{37-39}$ we are unable to determine whether our findings would have been different if data from other jurisdictions had been included. Despite evidence that the differences between Australian states with respect to sociodemographic and health economic indicators are small, ${ }^{40}$ it would be desirable to combine data from a larger number of Australian jurisdictions or, ideally, conduct a study across all Australian jurisdictions. However, such linked data either do not currently exist or are not available outside these states.

Our study has produced the first national estimates of mortality among ex-prisoners in Australia, within 4 weeks and 1 year of release from custody. The annual number of deaths among recently released prisoners is far greater than the annual number of deaths in custody, highlighting the extreme vulnerability of this population on return to the community. There is an urgent need to establish a national system for routine monitoring of ex-prisoner mortality and to continue the duty of care beyond the prison walls for this vulnerable population.

\section{ACKNOWLEDGEMENTS}

Stuart Kinner's work is supported by National Health and Medical Research Council (NHMRC) grants 401761, 456107, 409966 and 1004765. The original WA research was funded by the Criminology Research Council. We also thank the WA Departments of Health and Corrective Services for provision of data. Data collection in NSW was funded by NHMRC grant 222849. We thank staff from the NSW Department of Corrective Services for their assistance with data collection.

\section{COMPETING INTERESTS}

None relevant to this article declared (ICMJE disclosure forms completed).

\section{AUTHOR DETAILS}

Stuart A Kinner, PhD, Head, Justice Health Research ${ }^{1}$

David B Preen, BSc(Hons), PhD, Director, Centre for Health Services Research ${ }^{2}$

Azar Kariminia, BSc, MSc, PhD, Lecturer, Biostatistics and Database Program ${ }^{3}$

Tony Butler, PhD, MSc, Professor ${ }^{3}$

Jessica Y Andrews, BHSci/Comm(Hons), Research Assistant ${ }^{1}$

Mark Stoové, PhD, Head, HIV/STI Research ${ }^{1}$
Matthew Law, MA, MSc, PhD, Professor and Head, Biostatistics and Database Program ${ }^{3}$

1 Centre for Population Health, Burnet Institute, Melbourne, VIC.

2 School of Population Health, The University of Western Australia, Perth, WA.

3 Kirby Institute, University of New South Wales, Sydney, NSW.

\section{Correspondence: kinner@burnet.edu.au}

\section{REFERENCES}

1 Australian Bureau of Statistics. Prisoners in Australia, 2010. Canberra: ABS, 2010. (ABS Cat. No. 4517.0.)

2 Australian Bureau of Statistics. National Survey of Mental Health and Wellbeing: summary of results. Canberra: ABS, 2008. (ABS Cat. No. 4326.0.)

3 Martire KA, Larney S. Inadequate data collection prevents health planning for released prisoners [letter]. Med J Aust 2009; 191: 408-409.

4 Krieg AS. Aboriginal incarceration: health and social impacts. Med J Aust 2006; 184: 534-536.

5 Levy M. Australian prisons are still health risks [editorial]. Med J Aust 1999; 171: 7-8.

6 Butler T, Andrews G, Allnutt S, et al. Mental disorders in Australian prisoners: a comparison with a community sample. Aust N Z J Psychiatry 2006; 40: 272-276.

7 Butler T, Kariminia A, Levy M, Murphy M. The selfreported health status of prisoners in New South Wales. Aust N Z J Public Health 2004; 28: 344-350.

8 Kinner SA. Continuity of health impairment and substance misuse among adult prisoners in Queensland, Australia. Int J Prisoner Health 2006; 2: 101-113

9 Kinner SA, George J, Campbell G, Degenhardt L. Crime, drugs and distress: patterns of drug use and harm among criminally involved injecting drug users in Australia. Aust N Z J Public Health 2009; 33: 223-227.

10 Stewart L, Henderson C, Hobbs MST, et al. Risk of death in prisoners after release from jail. Aust N Z J Public Health 2004; 28: 32-36.

11 Kariminia A, Butler TG, Corben SP, et al. Extreme cause specific mortality in a cohort of adult prisoners - 1998 to 2002: a data-linkage study. Int J Epidemiol 2007; 36: 310-318.

12 Coffey C, Veit F, Wolfe R, et al. Mortality in young offenders: retrospective cohort study. BMJ 2003; 326: 1064.

13 Karaminia A, Law MG, Butler TG, et al. Suicide risk among recently released prisoners in New South Wales, Australia. Med J Aust 2007; 187: 387-390.

14 Borzycki M. Interventions for prisoners returning to the community. Canberra: Attorney-General's Department, 2005.

15 Degenhardt L, Day C, Dietze P, et al. Effects of a sustained heroin shortage in three Australian States. Addiction 2005; 100: 908-920.

16 Australian Institute of Health and Welfare. The health of Australia's prisoners 2009. Canberra: AlHW, 2010. (AlHW Cat. No. PHE 123.)

17 Kinner SA. Understanding mortality and health outcomes for ex-prisoners: first steps on a long road. Addiction 2010; 105: 1555-1556.

18 Australian Bureau of Statistics. Prisoners in Australia, 2008. Canberra: ABS, 2008. (ABS Cat. No. 4517.0.)

19 Australian Bureau of Statistics. Corrective Services, Australia, Sep 2009. Canberra: ABS, 2009. (ABS Cat. No. 4512.0.)

20 Randall D, Roxburgh A, Gibson A, Degenhardt L. Mortality among people who use illicit drugs: a toolkit for classifying major causes of death. Sydney: National Drug and Alcohol Research Centre, University of NSW, 2009
21 Binswanger IA, Stern MF, Deyo RA, et al. Release from prison - a high risk of death for former inmates. N Engl J Med 2007; 356: 157-165

22 Farrell M, Marsden J. Acute risk of drug-related death among newly released prisoners in England and Wales. Addiction 2008; 103: 251-255.

23 Bird SM, Hutchinson SJ. Male drugs-related deaths in the fortnight after release from prison: Scotland, 1996-99. Addiction 2003; 98: 185-190.

24 Merrall ELC, Kariminia A, Binswanger IA, et al. Metaanalysis of drug-related deaths soon after release from prison. Addiction 2010; 105: 1545-1554.

25 Degenhardt L, Rendle V, Hall W, et al. Estimating the number of current regular heroin users in NSW and Australia 1997-2002. NDARC Technical Report. Sydney: National Drug and Alcohol Research Centre, University of New South Wales, 2004.

26 Kariminia A, Law MG, Butler TG, et al. Factors associated with mortality in a cohort of Australian prisoners. Eur J Epidemiol 2007; 22: 417-428.

27 Hobbs M, Krazlan K, Ridout S, et al. Mortality and morbidity in prisoners after release from prison in Western Australia 1995-2003. Research and Public Policy Series no. 71. Canberra: Australian Institute of Criminology, 2006.

28 Dolan KA, Shearer J, White B, et al. Four-year follow-up of imprisoned male heroin users and methadone treatment: mortality, re-incarceration and hepatitis C infection. Addiction 2005; 100: 820-828.

29 Ministerial Council on Drug Strategy. National Corrections Drug Strategy 2006-2009. Canberra: MCDS, 2008

30 Kim D, Irwin KS, Khoshnood K. Expanded access to naloxone: options for critical response to the epidemic of opioid overdose mortality. Am J Public Health 2009; 99: 402-407.

31 Lenton SR, Dietze PM, Degenhardt $L$, et al. Naloxone for administration by peers in cases of heroin overdose. Med J Aust 2009; 191: 469.

32 Royal Commission into Aboriginal Deaths in Custody. National report. Canberra: Australian Government Publishing Service, 1991.

33 Curnow J, Larsen JJ. Deaths in custody in Australia: National Deaths in Custody Program 2007. Monitoring report no. 3. Canberra: Australian Institute of Criminology, 2009.

34 Sibthorpe B, Kliewer E, Smith L. Record linkage in Australian epidemiological research: health benefits, privacy safeguards and future potential. Aust $J$ Public Health 1995; 19: 250-256.

35 Brook EL, Rosman DL, Holman CDAJ. Public good through data linkage: measuring research outputs from the Western Australian Data Linkage System. Aust N Z J Public Health 2008; 32: 19-23.

36 Forsyth S, Kinner SA, Williams G, et al. Postrelease mortality among ex-prisoners in Queensland: a data linkage study. Proceedings of Public Health Association Australia Justice Health Conference. Justice health in Australia: beyond the convict era; 2009 Apr 6-7; Melbourne, Australia.

37 Hulse GK, English DR, Milne E, Holman CDJ. The quantification of mortality resulting from the regular use of illicit opiates. Addiction 1999; 94: 221-229.

38 Hall WD, Ross JE, Lynskey MT, et al. How many dependent heroin users are there in Australia? Med J Aust 2000; 173: 528-531.

39 Ezzati M, Lopez AD. Estimates of global mortality attributable to smoking in 2000. Lancet 2003; 362: 847-852.

40 Clark A, Preen DB, Ng JO, et al. Is Western Australia representative of other Australian states and territories in terms of key socio-demographic and health economic indicators? Aust Health Rev 2010; 34: 210-215.

Provenance: Not commissioned; externally peer reviewed.

(Received 11 Aug 2010, accepted 11 Apr 2011) 